\title{
Spatio-temporal variability in abundance, size and microhabitat associations of early juvenile Nassau grouper Epinephelus striatus in an off-reef nursery system
}

\author{
Craig P. Dahlgren*, David B. Eggleston \\ North Carolina State University, Department of Marine, Earth and Atmospheric Sciences, PO Box 8208, Raleigh, North \\ Carolina 27695-8208, USA
}

\begin{abstract}
Nassau grouper Epinephelus striatus is a reef fish that settles in off-reef nursery habitats before emigrating to coral reefs. Because little is known of its habitat use and population dynamics before moving onto reefs, we conducted monthly visual censuses from May to December (3 to 10 mo post-settlement) to quantify spatio-temporal variability in density, microhabitat use, and size-structure in a cohort of early juvenile Nassau grouper residing in an off-reef nursery system in the central Bahamas. Juvenile Nassau grouper density decreased significantly from August to September, but this decrease was small compared to a decrease of over $90 \%$ during the first 3 to 4 mo post-settlement, a pattern consistent with Type III survivorship. Throughout the study, Nassau grouper had a disproportionately high association with the macroalgae Laurencia sp., while other microhabitats (e.g. seagrass, corals) were usually used in proportion to their availability. Percent cover of Laurencia sp. significantly influenced spatial variability in fish density during May and June (4 to 5 mo post-settlement), but not later in the year. Spatial differences in juvenile Nassau grouper density later in the year were correlated with spatial variability in the size distribution of fish. Sites harboring disproportionately high numbers of large juveniles also had greater juvenile densities. Thus, microhabitat characteristics were determined to influence the spatial distribution of Nassau grouper up to 5 mo post-settlement, but the population appears to be influenced by size-dependent processes (e.g. predation or ontogenetic habitat shifts) after that time. Microhabitat characteristics, as well as spatially variable growth rates or size-dependent mortality may cause nursery areas to vary in their contribution to the local population at subsequent life history stages.
\end{abstract}

KEY WORDS: Nassau grouper $\cdot$ Epinephelus striatus $\cdot$ Population dynamics $\cdot$ Microhabitat

\section{INTRODUCTION}

Post-settlement habitat requirements can be a critical determinant of population distribution, abundance and size-structure for many marine species. For example, habitat selection at the time of settlement or

${ }^{*}$ Present address: Perry Institute for Marine Science/Caribbean Marine Research Center, 250 Tequesta Drive, Suite 304, Tequesta, Florida 33469, USA.

E-mail: cdahlgren@cmrc.org shortly thereafter (Sale et al. 1984, Levin 1991, Booth 1992, Öhman et al. 1998), and habitat-specific variability in post-settlement mortality may influence reef fish population distributions and abundance (Sale \& Ferrell 1988, Connell \& Jones 1991, Wellington 1992, Levin 1994, Tupper \& Boutilier 1995, Dahlgren \& Eggleston 2000). Differences in post-settlement growth rates among habitats can cause spatial variability in a population's size-structure (Jones 1986, Tupper \& Boutilier 1997) and may have additional population-level consequences, because predation risk, sexual maturation, 
and ontogenetic habitat shifts are often size-dependent (Thresher 1983, Werner \& Gilliam 1984, Ochi 1986, Sogard 1997, Dahlgren \& Eggleston 2000).

Because habitats are usually comprised of a complex mosaic of various microhabitats (e.g. quantitative or qualitative variability in habitat characteristics), habitat-dependent settlement rates or post-settlement mortality and growth rates, may be influenced by variability in microhabitat characteristics. For example, the distribution of microhabitat features providing highquality refuges (e.g. refuges scaled to fish body size) can impact local population abundance and sizestructure (Shulman 1984, Sale \& Ferrell 1988, Hixon \& Beets 1989, 1993, Levin 1994, Eggleston et al. 1997). Similarly, different microhabitat-specific growth rates and mortality risk, within a particular habitat, may influence distribution and abundance patterns (Dahlgren \& Eggleston 2000).

Much of our current understanding of early juvenile reef fish habitat requirements and population dynamics comes from studies conducted on damselfish (Pomacentridae) and other small reef fish species that settle directly to the reef (Sweatman 1983, 1988, Sweatman \& St. John 1990, Doherty 1991, Jones 1991 and references therein). Far less is known about habitat requirements and population dynamics of the early juvenile stages of large predators such as groupers (Serranidae), despite the ecological and commercial importance of these fish (but see Eggleston 1995, Ross \& Moser 1995, Light \& Jones 1997, Koenig \& Coleman 1998). Although it is recognized that many reefassociated species use off-reef nursery habitats such as seagrass beds, mangroves and macroalgae as settlement and nursery areas (reviewed by Parrish 1989; also Marx \& Herrnkind 1985, Herrnkind \& Butler 1986, Heck \& Weinstein 1989, Morton 1990, Eggleston 1995, Ross \& Moser 1995), we know little about the functional role of these habitats and the influence of microhabitat characteristics within these habitats on population distribution and abundance.

Our objective was to examine the early juvenile population dynamics of a coral reef fish, the Nassau grouper Epinephelus striatus, which recruits to off-reef nursery habitats. Specifically we wanted to (1) determine whether or not microhabitats within the nursery system are used by this fish in proportion to their availability; (2) identify whether or not microhabitat associations change as a function of time or body size; (3) quantify spatio-temporal variation in early juvenile Nassau grouper size and abundance within the nursery system; and (4) identify possible causes of observed spatial variability in juvenile Nassau grouper density. This work builds on previous studies of juvenile Nassau grouper distribution and abundance by extending investigations of microhabitat use and its influence on population dynamics to later juvenile stages, and examining how microhabitat associations influence distribution and abundance of juvenile grouper on larger scales.

\section{METHODS}

Study species. The Nassau grouper Epinephelus striatus is a large (up to $20 \mathrm{~kg}$ ), tropical western Atlantic serranid, and is one of the most important commercial fish species in the Caribbean, Bahamas, and Gulf of Mexico (Sadovy \& Eklund 1999). Furthermore, it is an important piscivore and benthic carnivore in coral reef systems, capable of influencing the structure of both fish and invertebrate populations and communities (Hixon \& Beets 1993, Eggleston et al. 1997, 1998). However, overfishing has resulted in a decline in Nassau grouper stocks throughout the Caribbean, and the fish is currently considered endangered or threatened throughout its range (IUCN 1996). Like many serranids, little is known about the early life history of the Nassau grouper, but recent studies have begun to describe settlement patterns and habitat use by early juveniles (Beets \& Hixon 1994, Eggleston 1995).

Although adult Nassau grouper commonly inhabit coral reefs, late larvae/early juveniles (25 to $35 \mathrm{~mm}$ total length, TL) recruit in distinct, wintertime pulses (Shenker et al. 1993, Colin et al. 1997) to shallow-water nursery habitats (Eggleston 1995). In the central Bahamas, Eggleston found the primary settlement and early juvenile habitat to be macroalgae-dominated creek systems (although newly settled juveniles may occasionally be found in rubble mounds or other habitats: C.P.D. pers. obs.). Within these nurseries, early juveniles reside within the interstices of macroalgal clumps (primarily Laurencia sp.) and macroalgaecovered coral clumps (primarily Porites porites covered by Laurencia sp.) for several months post-settlement, until they reach a size of 50 to $60 \mathrm{~mm}$ TL. Spatial distribution of small early juveniles ( $<50 \mathrm{~mm}$ TL) within nursery areas is strongly influenced by microhabitat characteristics, with increasing fish densities corresponding to increasing percent cover of the macroalgae Laurencia sp. for the first 2 mo post-settlement (Eggleston 1995). This relationship between fish density and percent cover of macroalgae is most probably a result of the refuge value of macroalgae for early juveniles (Dahlgren \& Eggleston 2000).

Qualitative observations suggest that by $60 \mathrm{~mm}$ TL, early juvenile Nassau grouper emerge from the interstices of macroalgae clumps and reside outside them. After emerging, they associate with other microhabitats (post-algal microhabitats), but remain within the 
macroalgae-dominated nursery system (Eggleston 1995). Because predation risk in post-algal habitats is high, the timing of this habitat shift may have a dramatic effect on juvenile survivorship and may disrupt distribution patterns determined by microhabitat characteristics shortly after settlement (Dahlgren 1998, Dahlgren \& Eggleston 2000). Nevertheless, we know little about the exact timing or size at which this microhabitat shift occurs, or what factors influence Nassau grouper populations at this life stage. Fish remain associated with these post-algal microhabitats until they reach a size of 110 to $170 \mathrm{~mm}$ TL (usually 9 to $12 \mathrm{mo}$ post-settlement), when they apparently leave the macroalgal nursery system and take up residence on nearby patch reefs (Eggleston 1995).

Study sites. Surveys of microhabitat utilization, abundance, and size structure of young-of-the-year juvenile Nassau grouper were conducted during 1994 in shallow (1 to $4 \mathrm{~m}$ deep) tidal creeks in the vicinity of the Caribbean Marine Research Center (CMRC), Lee Stocking Island, Bahamas $\left(23^{\circ} 45^{\prime} \mathrm{N}, 76^{\circ} 10^{\prime} \mathrm{W}\right.$; Sites B1 to B4: Fig. 1). Surveys were restricted to this nursery system because it is the most important habitat for early juvenile Epinephelus striatus, with juvenile density orders of magnitude higher in this habitat than in other nearby habitats (Eggleston 1995). A detailed description of this nursery system is provided by Eggleston (1995). Briefly, tidal creeks were 60 to $120 \mathrm{~m}$ wide, fringed with mangroves, and contained expansive areas $\left(>8000 \mathrm{~m}^{2}\right)$ dominated by macroalgae (primarily Laurencia sp., but Batophora sp., Halimeda sp., Penicillus sp., and Cladophora sp. were also present). Other physically complex microhabitats in the tidal creeks included seagrass (Thalassia testudinum), small coral clumps (primarily Porites porites), and sponges. The bottom also contained many crevices and solution holes. Sites B1 and B3 were located within $100 \mathrm{~m}$ of each other, but were separated by a man-made causeway with water exchange between sites restricted through a $3 \mathrm{~m}$-diameter pipe (Fig. 1). Sites B2 and B4 were separated in a similar manner, with two 3 m-diameter pipes connecting the sites. All sites were subject to strong tidal currents, sometimes exceeding $50 \mathrm{~cm} \mathrm{~s}^{-1}$ (Eggleston 1995), and high visibility (ca 10 to $20 \mathrm{~m}$ ).

Sampling protocol. SCUBA divers conducted visual censuses of size-specific microhabitat use and abundance of early juvenile Nassau grouper at Sites B1 to B4 (Fig. 1) following a large settlement pulse in early February 1994 (Eggleston \& Dahlgren unpubl. data). Because post-settlement Nassau grouper re- main within the interstices of macroalgal clumps and are undetectable by visual census techniques until approximately 3 mo after settlement (Eggleston 1995), monthly visual censuses started in May and continued through December at all 4 sites (except Site B4, which was not sampled in June due to logistical constraints).

Visual census techniques generally followed those described by Eggleston (1995). Each site was divided into eight $10 \times 60 \mathrm{~m}$ sections (running perpendicular to the shoreline) and marked with buoys. During monthly censuses from July to September and in December, 6 (of the possible 8) separate sections were randomly chosen and censused at each site. During each census, paired divers counted, estimated size ( $\mathrm{mm} \mathrm{TL}$ ), and recorded habitat use (except in December when habitat associations were not recorded) of each juvenile Nassau grouper within a $2 \times 60 \mathrm{~m}$ band transect haphazardly located within the randomly chosen $10 \mathrm{~m}$ wide area. Fish sizes were estimated by comparing fish to a ruler attached to the far end of a $70 \mathrm{~cm}$ rod held out from the diver (Bohnsack \& Bannerot 1986). Percent cover of 5 benthic microhabitat categories (each covering $>1 \%$ of the total area) were also estimated for each band. The microhabitat categories were (1) Lau-

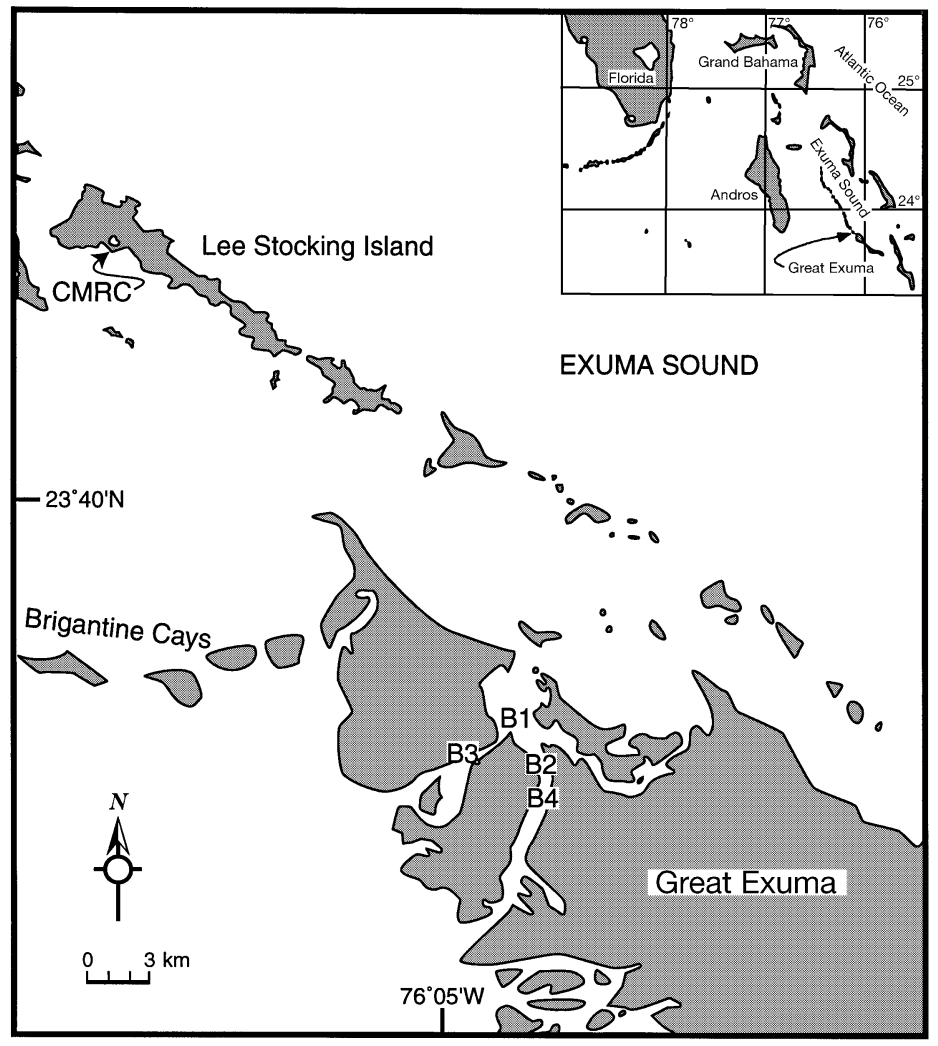

Fig. 1. Study sites B1 to B4 near Great Exuma Island and the Caribbean Marine Research Center (CMRC) on Lee Stocking Island, Exuma Cays, Bahamas 
rencia sp. (including Laurencia-covered coral clumps); (2) coral (predominantly Porites porites, including both live coral and coral rubble); (3) seagrass Thalassia testudinum; (4) other algae (including Batophora sp., Cladophora sp. Halimeda sp. and Penicillus sp.); and (5) sponges. The percent cover of each microhabitat, as well as bare substrate (usually sand or a thin sand veneer over rock), was estimated visually. To increase the accuracy of estimates, habitat data were recorded every $20 \mathrm{~m}$, and then combined for each band. Within each band, 2 divers independently estimated percent cover of all habitats. Although differences in percent cover estimates did not vary much between divers ( $<10 \%$ in all cases) diver estimates were averaged to reduce individual diver bias. The average percent cover of each habitat per band was used in statistical analyses. The total area censused at each of 4 sites on a monthly basis was $720 \mathrm{~m}^{2}$.

Censuses during May and June followed a slightly different protocol. Within a randomly chosen $10 \times 60 \mathrm{~m}$ section from each site (out of 8 possible bands), a $2 \times$ $60 \mathrm{~m}$ band transect was haphazardly selected and divided into twelve $2 \times 5 \mathrm{~m}$ segments (herein referred to as 'short'-band transects). Eight randomly chosen shortband transects were visually censused for grouper as described above, and the percent cover of all habitat types present in the short-band transects was estimated by each diver and averaged between divers for statistical analyses. Thus, the sampling unit or area differed from the previously described band transects during May and June. This approach was used to be consistent with an Exuma Sound-wide survey of Caribbean spiny lobster and Nassau grouper that was part of CMRC's Fisheries Oceanography and Recruitment in the Caribbean and Subtropics research program (Lipcius et al. 1997). The total area censused per month at each site in May and June was $80 \mathrm{~m}^{2}$. The May and June data provided information on size-dependent habitat use during the period when fish were exhibiting an ontogenetic habitat shift from the interstices of macroalgal clumps to other microhabitats outside the macroalgae. Because short-band transects were not conducted simultaneously with the previously described band transects ('long'-band transects that were conducted from July to September and in December), it was impossible to assess whether there were differences in the sampling efficiency of the different techniques, so May and June data were not statistically compared with July to December data. The difference in band transect size between May and June and July to December could potentially confound estimates of fish density over time. This potential bias should be in favor of detecting increased densities and decreased variability as one switched from the short to long transects, owing to the patchy nature of fish distribution in this habitat (Eggle- ston 1995). This was not the case, since fish density declined over time (see Fig. 5). Nevertheless, density estimates in May and June were not statistically compared with estimates for July to December.

Microhabitat abundance and fish associations. Whether or not the abundance of early juvenile Nassau grouper was distributed among major microhabitats (e.g. Laurencia sp., coral, seagrass) at random was determined by comparing the observed number of juveniles associated with each habitat type during monthly censuses (May to September) to the number of juveniles expected to be associated with each habitat type based on its percent cover. Rare habitats were excluded from this analysis because their abundance was difficult to quantify accurately. The expected numbers of fish in each major habitat type were calculated for each month using the following equation:

$$
E_{h j}=\sum\left(n_{i j} p_{h i j} / \sum p_{h i j}\right)
$$

where $n_{i j}=$ the total number of fish (excluding fish observed in habitats comprising $<1 \%$ of the area sampled) observed at Site $i$ in Month $j$ (May to September); and $p_{\text {hij }}=$ the percent cover of habitat $h$ (Laurencia sp., coral, seagrass, other algae, sponges) at Site $i$ during Month $j$. Because fish were never observed over sand, the percent cover of sand substrate was omitted from all statistical analyses. All habitat-specific observed and expected values were statistically compared for each month separately with a loglinear G-test using Williams's correction for continuity (Zar 1984, Sokal \& Rohlf 1995).

To identify which microhabitats were responsible for significant differences in proportional habitat use detected with the G-test, monthly transect censuses were used to calculate a habitat-specific index of association (A) for each site and month (May to September). Our index of association was adapted from other species association and resource selection indices (e.g. Pielou 1969, Strauss 1979). Habitat-specific indices of association enabled us to compare fish associations with various microhabitats and detect changes in microhabitat associations over time and among size-classes using repeated-measures ANOVA models. Because sites were the experimental unit that was repeatedly sampled, rather than individual transects within a site (and we were not interested in examining within-site variability), fish and habitat data from each site were pooled for each month to calculate monthly habitatspecific indices of association. Alternative approaches, such as multiple G-tests or chi square comparisons, were not used to avoid increased probability of Type I errors. The habitat-specific index of association was calculated using the following equation:

$$
A_{h i j}=\left(n_{h i j} / n_{i j}\right)-\left(p_{h i j} / p_{i j}\right)
$$


where $n_{h i j}=$ the number of fish observed in Habitat $h$ at Site $i$ during Month $j_{i} n_{i j}=$ the total number of fish observed at Site $i$ in Month $j_{i} p_{h i j}=$ the percent cover of Habitat $h$ at Site $i$ during Month $j_{i}$ and $p_{i j}=$ the percent cover of all major habitats (excluding sand and rock) at Site $i$ during Month $j$. The number of fish in a particular habitat $\left(n_{h i j}\right)$ may result from either habitat selection or differential mortality among habitat categories. Index of association values can range from -1.0 to +1.0. A positive index of association indicated that fish were positively associated with a particular habitat type, a negative value indicated a negative association, and zero indicated that the habitat was used in proportion to its availability. To test the null hypothesis that fish were associated with each habitat in proportion to its availability, a Student's $t$-test was used to determine whether or not monthly means of each habitat-specific index of association were significantly different from zero.

To determine whether habitat associations changed as a function of time or fish size (length), monthly habitat-specific indices of association were re-calculated for fish grouped into 3 size-classes at each site. Sizeclasses were small ( $<50 \mathrm{~mm} \mathrm{TL}$ ), medium (50 to $69 \mathrm{~mm}$ $\mathrm{TL}$ ), and large ( $\geq 70 \mathrm{~mm} \mathrm{TL}$ ), based on qualitative observations of habitat use described by Eggleston (1995). The small size-class corresponded to the size of fish that were typically found in the interstices of Laurencia sp. clumps, and the large size-class corresponded to the size typically found in post-algal microhabitats. The medium size-class corresponded to the expected size of the ontogenetic microhabitat shift within the nursery system, from living within the interstices of Laurencia sp. clumps to living outside them and associated with post-algal habitats (Eggleston 1995). Mean monthly size- and habitat-specific indices of association were compared among fish size-classes and sampling months with a 1-way repeated-measures ANOVA model with fish size-class (small, medium, and large) as the factor and month (May and June analyzed separately from July to September) as the repeated measure. Due to changing fish size distributions over time, comparisons of size-specific habitat associations were limited to small and medium sizeclasses in May and June, and medium and large sizeclasses from July to September. An $F_{\max }$-test was used to confirm the ANOVA assumption of variance homogeneity.

In addition to the 5 major microhabitats ( $>1 \%$ cover), grouper were sometimes observed in solution holes, ledges, and crevices ('other habitats') that covered $<1 \%$ of the area at the study sites. The shelters provided by these habitats were often relatively large compared to fish body size (C.P.D. pers. obs.), so they were expected to be used preferentially by large fish, but not small fish (i.e. use of these habitats was not random with respect to size-class) (Hixon \& Beets 1993). To test if crevice use was size-dependent, a $G$-test was conducted comparing the number of fish of each sizeclass observed to the number of fish expected to use 'other habitats.' Expected values for each fish sizeclass were calculated by multiplying the total number of fish associated with 'other habitats' by the proportion of each size-class observed in the overall population.

Spatio-temporal variation in Nassau grouper density and size. To determine if density of young-of-theyear Nassau grouper $(<110 \mathrm{~mm}$ TL) varied among sites, over time, and as a function of macroalgal (Laurencia sp.) percent cover, May and June and July to December site-specific densities of Nassau grouper were compared using separate repeated-measures ANCOVA models. Fish $\geq 110 \mathrm{~mm}$ TL were excluded from the analysis because they were assumed to have recruited to the nursery areas prior to the recruitment pulse in early February 1994. In repeated-measures ANCOVA analyses, fish density in each band (numbers per $\mathrm{m}^{2}$ ) was the response variable, site (B1 to B4) was the factor, month was the repeated measure (used as a blocking term), and the percent cover of Laurencia sp. from each band was the covariate. Laurencia sp. was selected as a covariate in this analysis because fish showed a positive association with Laurencia sp. (see 'Results'), and an earlier study indicated that there was a significant linear relationship between early juveniles and Laurencia sp. percent cover 1 to 2 mo postsettlement (Eggleston 1995). The model was initially run with all factor-by-covariate interactions to ensure homogeneous regression slopes for all factor levels (Underwood 1997). Non-significant interactions were dropped from the final model to test the effects of site, month and percent cover of Laurencia sp. on fish density. The ANCOVA assumption of homogeneity of variances was tested with an $F_{\max }$-test, and the data were $\log (x+1)$-transformed for the July to December analysis to correct for heterogeneity in variances (Sokal \& Rohlf 1995). When site was a significant factor, differences among sites were detected using a Ryan's $Q$-test as recommended by Day \& Quinn (1989). When the repeated measure was significant, lower-level ANOVA comparisons of adjacent repeated measures were conducted to detect differences among months.

Another objective of the study was to describe variability in the size distribution of the cohort over time and among sites. Variation in the frequency of fish size-classes among sites was examined to determine if each size occurred in proportion to the total number of fish at each site. This was done by comparing the observed abundance of each fish size-class (pooled across months) at each site, to the expected number of 

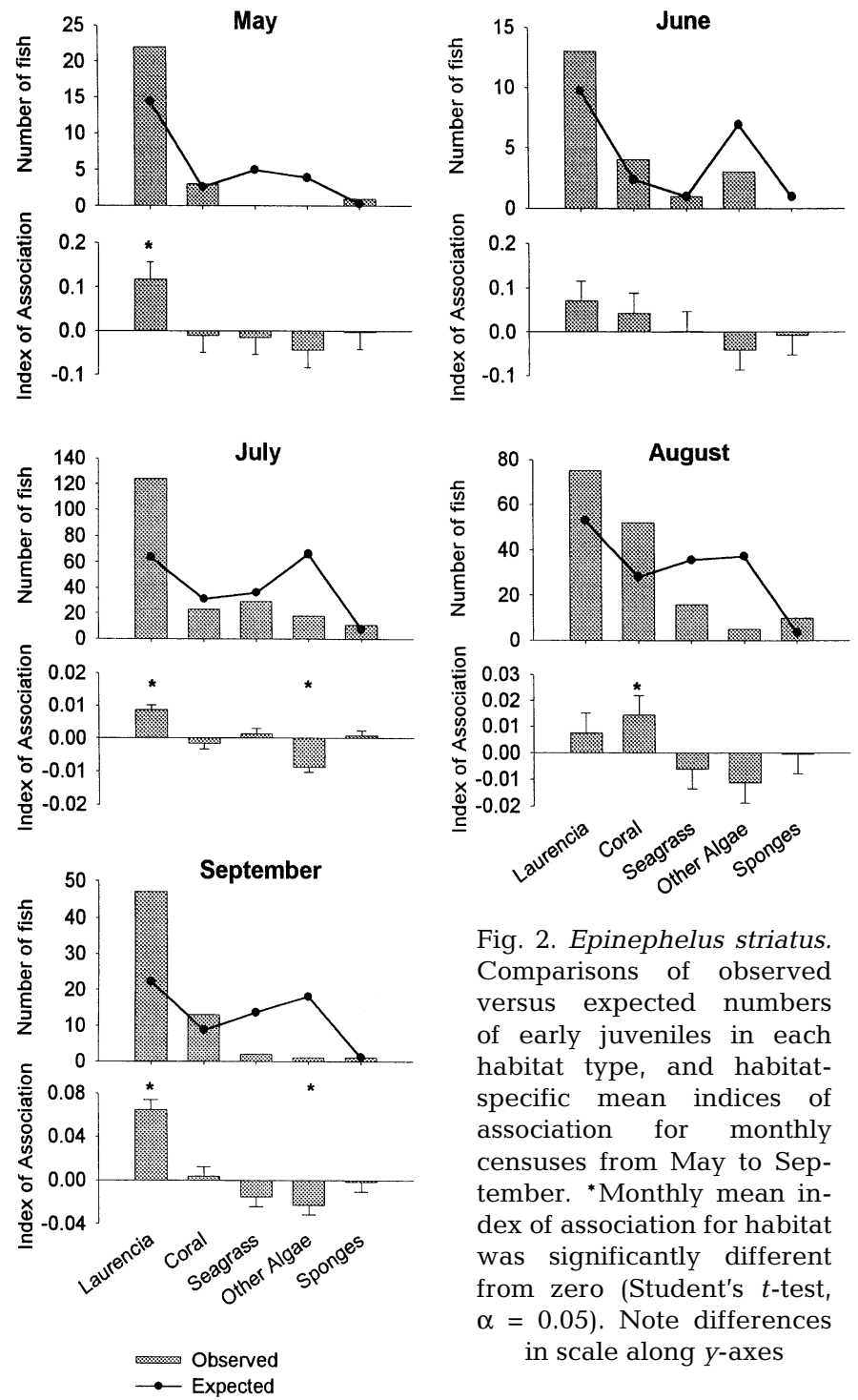

fish in each size-class at each site. Expected values were calculated with the following equation:

$$
E_{i k}=\sum n_{j k}\left(n_{i j} / n_{j}\right)
$$

where $n_{i j}=$ the number of fish observed at Site $i$ (B1 to B4) in Month $j$ (May and June, July to September and in December) ${ }_{i} n_{j}=$ the total number of fish observed in Month $j_{i}$ and $n_{j k}=$ the total number of fish in Size-class $k$ (small, medium, large) in Month $j$. Observed and expected values for each size-class were compared with a log linear $G$-test using Williams's correction for continuity (Zar 1984, Sokal \& Rohlf 1995).

\section{RESULTS}

\section{Microhabitat abundance and fish associations}

Within the nursery system, Laurencia sp. was the most abundant microhabitat (31.3\% cover) averaged across all sites and months, followed by other species of macroalgae $(16.8 \%)$, seagrass $(10.8 \%)$, coral $(9.7 \%)$, and sponges $(1.9 \%)$. The remaining substrate $(29.5 \%)$ was bare sand or rock covered by a thin veneer of sand. Early juvenile Epinephelus striatus were observed associated with all microhabitats except sand. Out of 546 total fish observed, 474 were associated with the 5 major microhabitats. During 4 of 5 months, fish did not use all microhabitats in proportion to their availability ( $G$-test; May: $G_{4}=21.54, \mathrm{p}<0.001 ;$ June: $G_{4}=6.43, \mathrm{p}>$ 0.05 ; July: $G_{4}=98.51, \mathrm{p}<0.0001$; August: $G_{4}=$ 90.02, p < 0.0001; September: $G_{4}=66.81, \mathrm{p}<$ 0.0001 ; Fig. 2). There were significantly more fish

Table 1. Epinephelus striatus. Result of repeated-measures ANOVA examining changes in habitat-specific indices of association among fish size-classes (i.e. 'between' subject factors) and over time (i.e. 'within' subject factors). Index of association is a measure of proportional habitat use based on habitat availability. During May and June, the levels of fish size were small and medium; from July to September, the levels of fish size were medium and large. ns: $\mathrm{p}>0.05 ;{ }^{*} \mathrm{p}<0.05$

\begin{tabular}{|c|c|c|c|c|c|c|c|}
\hline \multirow[t]{2}{*}{ Source } & & \multicolumn{3}{|c|}{ May, June } & \multicolumn{3}{|c|}{ July-September } \\
\hline & & df & MS & $F$ & $\mathrm{df}$ & MS & $F$ \\
\hline \multicolumn{8}{|l|}{ Laurencia sp. } \\
\hline \multirow[t]{2}{*}{ Between: } & Size & 1 & 0.5817 & $2.49 \mathrm{~ns}$ & 1 & 0.0029 & $0.09 \mathrm{~ns}$ \\
\hline & Error & 3 & 0.2336 & & 6 & 0.0334 & \\
\hline \multirow[t]{3}{*}{ Within: } & Month & 1 & 0.0094 & $0.91 \mathrm{~ns}$ & 2 & 0.2301 & $3.98^{*}$ \\
\hline & Size $\times$ Month & 1 & 0.4129 & $0.80 \mathrm{~ns}$ & 2 & 0.0204 & $0.35 \mathrm{~ns}$ \\
\hline & Error & 3 & 0.5732 & & 12 & 0.0578 & \\
\hline \multicolumn{8}{|l|}{ Seagrass } \\
\hline \multirow[t]{2}{*}{ Between: } & Size & 1 & 0.0047 & $2.13 \mathrm{~ns}$ & 1 & 0.0098 & $2.59 \mathrm{~ns}$ \\
\hline & Error & 3 & 0.0022 & & 6 & 0.0038 & \\
\hline \multirow[t]{3}{*}{ Within: } & Month & 1 & 0.0104 & $0.87 \mathrm{~ns}$ & 2 & 0.0435 & $4.81^{*}$ \\
\hline & Size $\times$ Month & 1 & 0.0247 & $2.06 \mathrm{~ns}$ & 2 & 0.0055 & $0.61 \mathrm{~ns}$ \\
\hline & Error & 3 & 0.0120 & & 12 & 0.0090 & \\
\hline
\end{tabular}


associated with Laurencia sp. (May, July, September) and coral (August) than expected (i.e. index of association $>0$; $t$-test $\mathrm{p}<0.05$; Fig. 2), and significantly fewer fish associated with other macroalgae (July and September) than expected (i.e. index of association $<0$; $t$-test $\mathrm{p}<0.05$; Fig. 2). Fish used all other habitat types in proportion to their availability each month, despite non-significant trends suggesting that seagrass and sponges were underrepresented and coral was overrepresented most months.

In general, microhabitat associations of Nassau grouper varied little according to month or fish size. Laurencia sp. and seagrass were the only habitats for which indices of association changed significantly between months (Fig. 2, Table 1). The association with Laurencia sp. was consistently positive, and increased significantly between July and September $\left(F_{1,6}=6.02\right.$, $\mathrm{p}<0.05$; Fig. 2). Fish association with seagrass decreased significantly from July to August $\left(F_{1,6}=\right.$ $6.98, \mathrm{p}<0.05$; Fig. 2). Habitat-specific indices of association did not differ between size-classes for any month (Table 1).

A relatively high percentage $(13 \%)$ of juvenile Nassau grouper observed were associated with habitats that comprised $<1 \%$ of the seafloor in transects. Most of the 72 juvenile grouper that were observed in rare habitats were associated with solution holes or ledges in hardbottom areas $(\mathrm{n}=67)$. They were also observed to use cinderblocks, aluminum cans and pieces of mangrove roots or branches that were on the bottom $(n=5)$. Use of ledges and solution holes by each size-class did not differ from expected $\left(G_{2}=5.10, \mathrm{p}<\right.$ 0.10 ), but showed a non-significant trend towards increased use of these habitats by medium and large fish (Fig. 3).

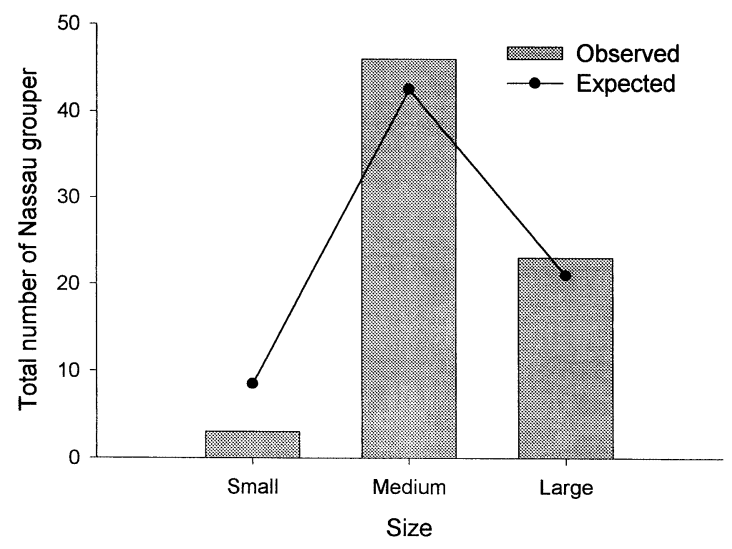

Fig. 3. Epinephelus striatus. Comparisons of observed versus expected numbers of fish from each size-class associated with ledges, solution holes and other microhabitats that comprised $<1 \%$ of the total area censused. See 'Results' for significance levels
Table 2. Epinephelus striatus. Results of repeated-measures ANCOVA comparing juvenile density among sites (i.e. 'Between' subject factors) with Laurencia sp. as a covariate and months as a blocking factor (i.e. 'Within' subject factor) during May and June censuses (short-band transects) and July to December censuses (long-band transects). Lowerlevel repeated-measures ANOVA comparisons of monthly means are presented for significant month effects (July to December). ns: $\mathrm{p}>0.05 ;{ }^{*} \mathrm{p}=0.0001 ; \mathrm{n}$ : numerator $\mathrm{df}_{i}$ $\mathrm{d}$ : denominator $\mathrm{df}$

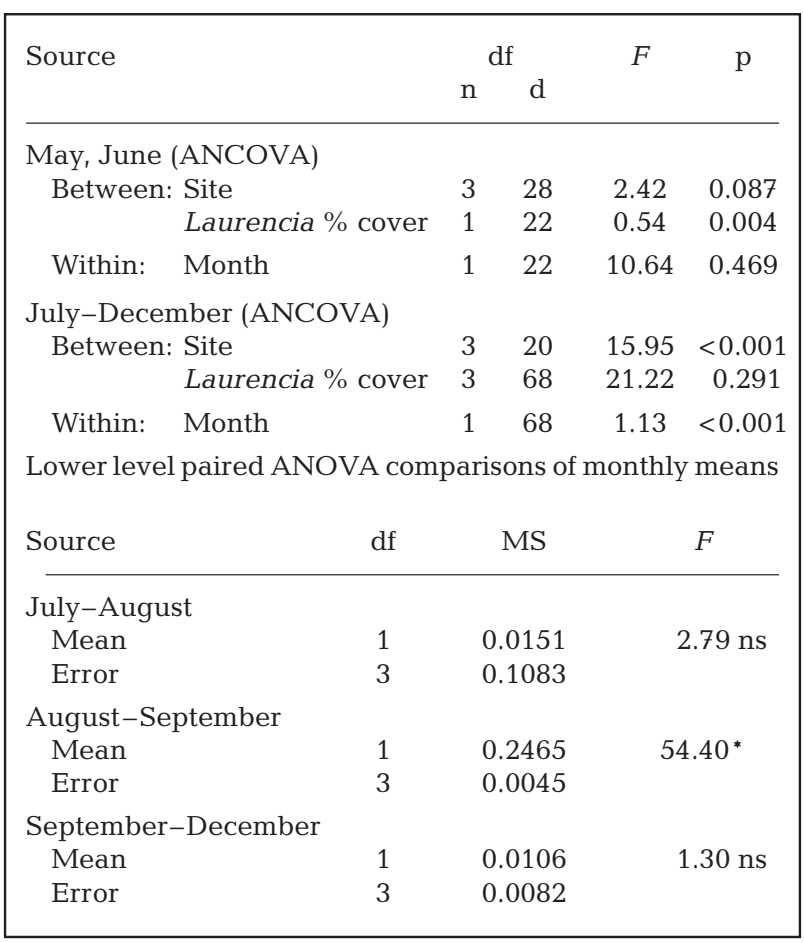

\section{Spatio-temporal variation in Nassau grouper density and size}

In May and June, there was a significant and positive linear relationship between early juvenile Nassau grouper density and Laurencia sp. percent cover; however, neither month nor site effects were significant, despite a trend towards higher density at Sites B2 and B4 (Table 2, Fig. 4). In contrast, from July to December, both month and site had significant influence on grouper density, but percent cover of Laurencia sp. did not (Table 2). Fish densities were significantly higher at Sites B2 and B4 from July through December (Fig. 4, Table 2). The overall density of early juvenile Nassau grouper was similar between May and June and between July and August, but declined significantly across all sites from August to September, after which it did not vary (Fig. 5, Table 2).

The size of young-of-the-year Nassau grouper ranged from 40 to $100 \mathrm{~mm}$ TL from May to December. Small fish $(<50 \mathrm{~mm} \mathrm{TL})$ were observed during May 

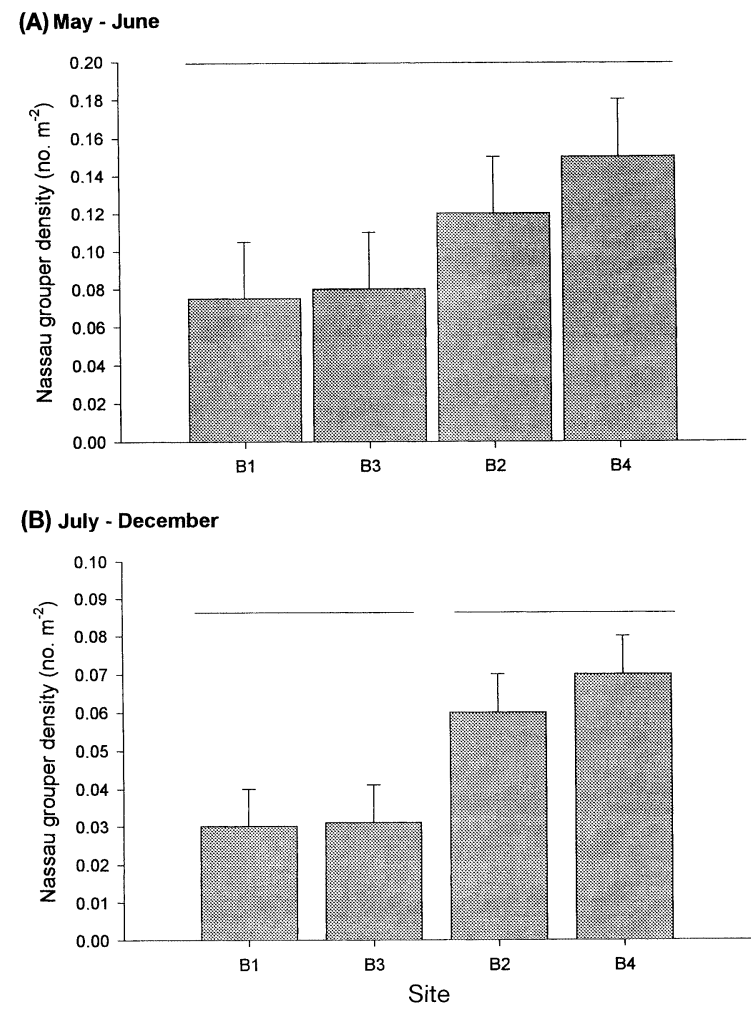

Fig. 4. Epinephelus striatus. Mean densities of early juveniles at Sites B1 to B4 from May and June and from July to December (pooled across these months). Error bars represent $1 \mathrm{SE}$; lines above histogram bars: sites that did not differ significantly from each other (Ryan's $Q$-test, $\alpha=0.05$ )

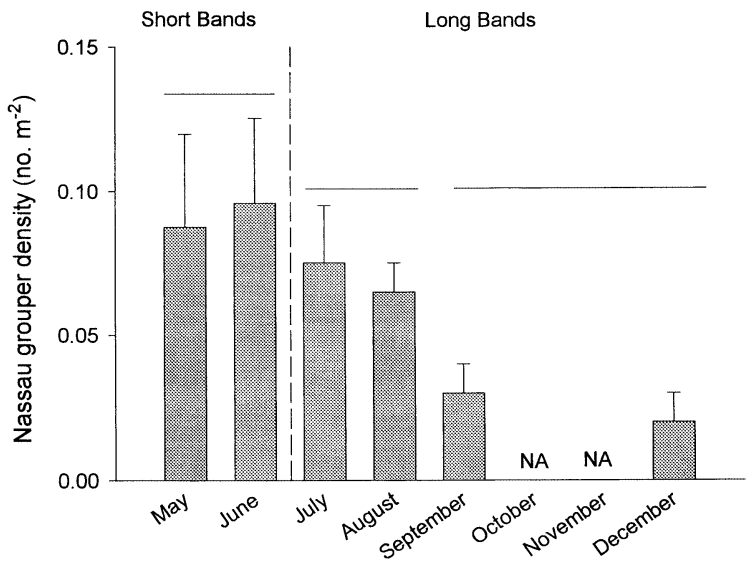

Fig. 5. Epinephelus striatus. Change in density over time from May through December 1994. Dashed line separates monthly censuses using different sampling techniques (see 'Methods' for description of sampling techniques). Error bars represent 1 SE. NA: no sampling was conducted during the respective month. Monthly means connected by line do not differ significantly (Ryan's $Q$-test, $\alpha=0.05$ ). No statistical comparisons were made between months using different sampling techniques and June (Fig. 6), and 1 small fish was observed in July. Medium fish were observed during all months, and large fish were only observed from June to December, with the highest percentages of large fish observed in December (Fig. 6). Although fish as small as $40 \mathrm{~mm}$ TL were observed in May and June (100 to $130 \mathrm{~d}$ post-settlement), $>50 \%$ of observed fish were 45 to $50 \mathrm{~mm}$ TL, suggesting that most fish in this size range shift out of the interstices of macroalgal clumps. Small and medium fish were distributed proportionally among sites ( $G$-test; small: $G_{3}=0.57, \mathrm{p}>0.05$; medium: $G_{3}=6.39, \mathrm{p}>0.05$ ), whereas large fish were not (G-test; $G_{3}=14.49, \mathrm{p}<0.01 ;$ Fig. 7). There were fewer large fish than expected at the 2 northern sites, B1 and B3, and more large fish than expected at Sites B2 and B4 (Fig. 7).

\section{DISCUSSION}

We documented spatio-temporal variability in distribution and abundance and habitat associations for a population of early juvenile Epinephelus striatus residing in an off-reef nursery system. Our major findings were: (1) young-of-the year Nassau grouper density decreased significantly during the study period, (2) habitat use was non-random, (3) the macroalgae Laurencia sp. influenced the spatial distribution of fish for 4 mo after settlement, but (4) distribution and abundance of juvenile Nassau grouper were decoupled from the percent cover of Laurencia sp. 5 mo post-settlement. Although grouper density was decoupled

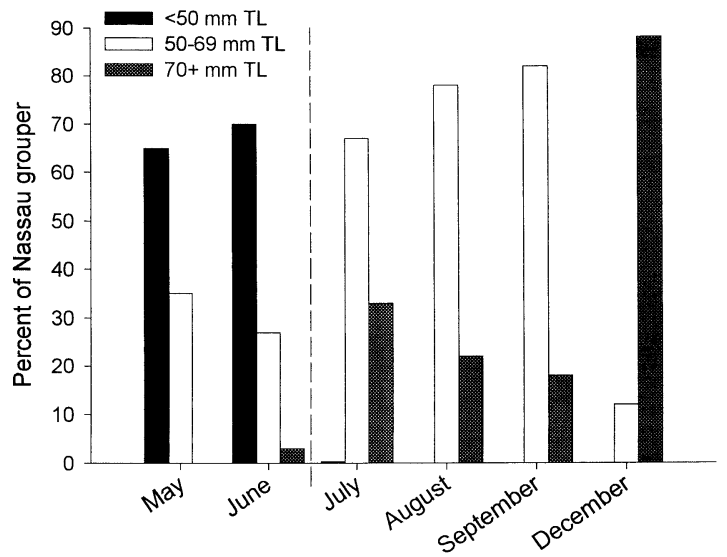

Fig. 6. Epinephelus striatus. Monthly size distribution of juveniles pooled across 4 study sites. Percent composition of monthly densities by each of the 3 fish size-classes is shown. Dashed line separates short-band transects conducted in May and June from long-band transects conducted in July to December. See 'Methods' for a description of short-versus long-band transects. TL: total length 


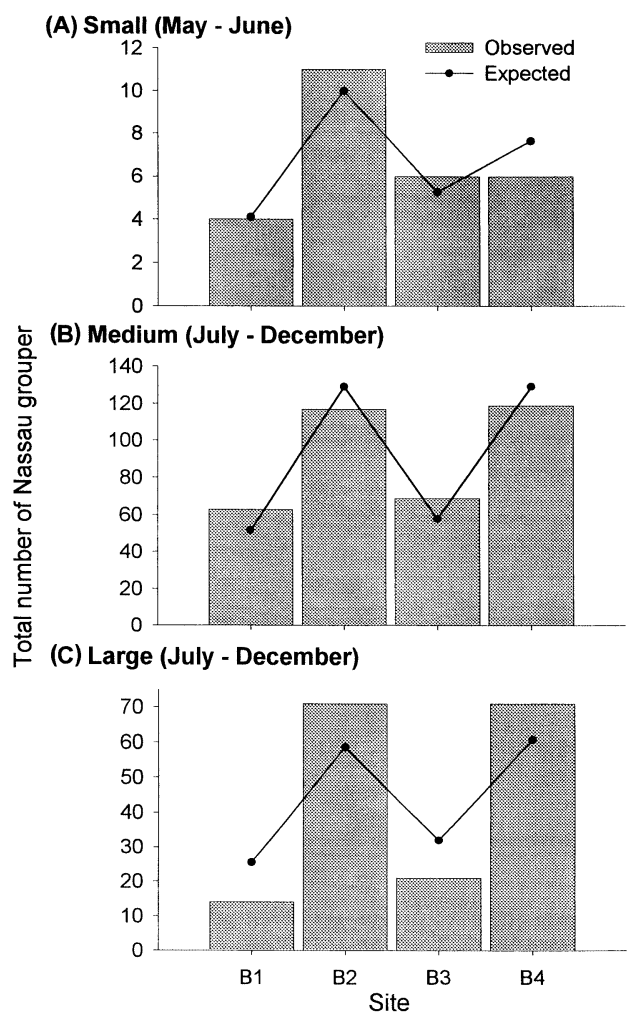

Fig. 7. Epinephelus striatus. Comparisons of observed versus expected numbers among sites for small $(<50 \mathrm{~mm} \mathrm{TL})$, medium (50 to $69 \mathrm{~mm}$ TL), and large (70+ mm TL) fish. Expected values represent proportional distribution of sizeclasses among sites. Site-specific abundances were across May and June for small fish, and across July to December for medium and large fish. See 'Results' for significance levels

from Laurencia sp. by July, differences in density among sites were detected and correlated with spatial variability in the population's size structure, with sites harboring a greater proportion of large grouper having higher overall densities. Our study provides new insights into the importance of microhabitat characteristics and other factors that influence population dynamics in off-reef nursery systems. Moreover, our work greatly increases our knowledge of habitat use, ontogenetic habitat shifts, and population dynamics of this important species.

Our observation of a decrease in young-of-the-year Nassau grouper density in a nursery system from August to September may have resulted from high mortality rates at this time, or an ontogenetic habitat shift out of the nursery system. Previous findings of a decrease in Nassau grouper density in the nursery system coupled with an increase in density on patch reefs by 10 mo post-settlement suggest that our observed decrease in density is due to this habitat shift (Eggleston 1995). Comparison of juvenile Nassau grouper density in our study 3 to 11 mo post-settlement to the same cohort's density $1 \mathrm{wk}$ to $1 \mathrm{mo}$ after settlement (Eggleston 1995) suggests that a $90 \%$ decrease in density occurred within the first 3 mo post-settlement (Fig. 8). Although differences in density may be due to differences in sampling techniques used during different months (i.e. suction sampling in February and March, 'short'-band transects in May and June, 'long'band transects from July to December: see Eggleston 1995 for further description of techniques), each technique was highly efficient at sampling fish of the appropriate size-class and habitat (Eggleston 1995). Decreased density over time may also be due to movement out of the nursery system to reefs; however the greatest decrease in density occurred before movement out of the nursery system took place (Eggleston 1995). The decrease in density of early juvenile Nassau grouper in the macroalgal nursery system from the time of settlement until 11 mo post-settlement is indicative of a Type III survivorship in which mortality is disproportionately high early in life. This survivorship pattern suggests that population dynamics of early juveniles may have a strong effect on juvenile and adult populations (Hixon 1991).

During the first 1 to 2 mo post-settlement, Eggleston (1995) observed a significant linear relationship between the percent cover of the macroalgae Laurencia sp. and early juvenile Nassau grouper density, with

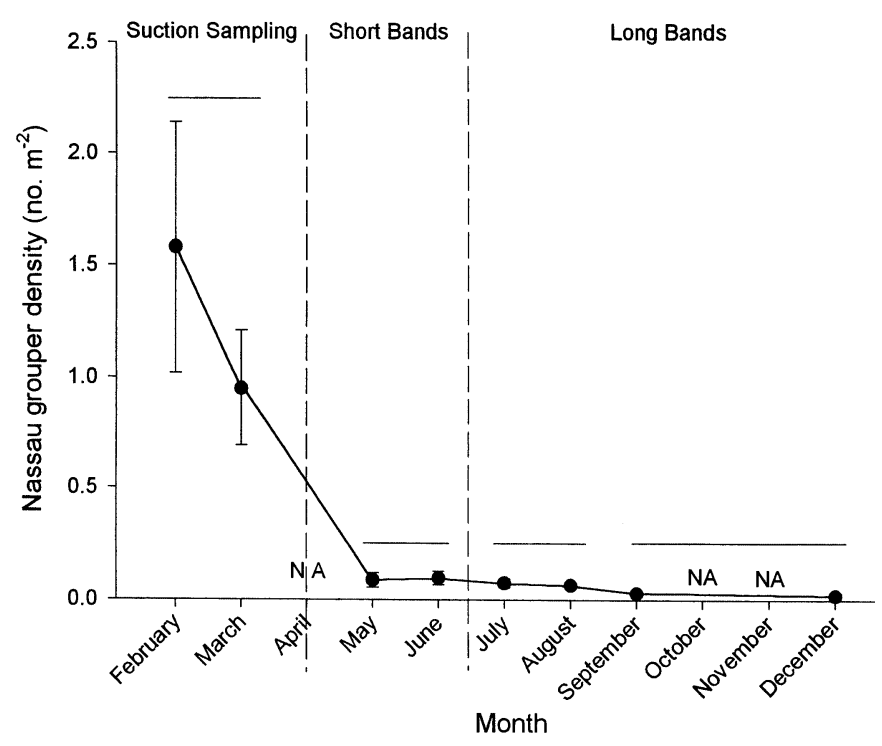

Fig. 8. Epinephelus striatus. Survivorship curve indicating the change in density over time from settlement in February through December 1994 (February and March values are from Eggleston 1995). Dashed lines separate monthly censuses using different sampling techniques; the techniques are listed at the top of figure (see 'Methods' for description of sampling techniques). NA: no sampling was conducted during the respective month 
areas of high Laurencia sp. cover having high fish density. We found this significant relationship to persist for up to 4 mo post-settlement. This is probably due to the refuge value of Laurencia sp. for Nassau grouper at this time, when they are commonly found residing within the interstices of Laurencia sp. clumps (Dahlgren \& Eggleston 2000). In many tropical and temperate systems, the post-settlement abundance, survivorship and spatial distribution of reef fish is influenced by the characteristics and distribution of various microhabitats (e.g. Levin 1991, Carr 1994, Friedlander \& Parrish 1998, Tolmieri 1998a,b and references therein). Nevertheless, the influence of microhabitat on fish populations may be limited to small spatial scales or only to early post-settlement stages (e.g. Tolmieri 1998a,b).

After 4 mo, fish still maintained a positive association with Laurencia sp. in general, but density was not significantly related to percent cover of Laurencia sp. The decoupling of early juvenile Nassau grouper density from Laurencia sp. percent cover is probably the result of several factors. The first is an ontogenetic habitat shift in which fish emerged from the interstices of Laurencia sp. clumps to live outside them and use other microhabitats such as coral, sponges, solution holes, other macroalgae and seagrass within the nursery system. Although solution holes and ledges in rocky areas were relatively rare in our habitat surveys $(<1 \%$ of the total area), they are an important post-algal habitat for Nassau grouper within this nursery, with over $12 \%$ of all fish observed associated with these habitats. Other studies of reef fish habitat use show that fish may use specific settlement microhabitats, but become more generalized in their habitat use as they grow (Jones 1984, Light \& Jones 1997). Although the microhabitat shift out of Laurencia sp. had previously been qualitatively documented to occur by the time Nassau grouper reach $6.0 \mathrm{~cm} \mathrm{TL}$, we observed fish as small as $4.0 \mathrm{~cm}$ TL living outside Laurencia sp. and associated with other microhabitats. The observed ontogenetic habitat shift is expected to be the result of fish achieving both a relative refuge-in-size from predation that reduces their dependency on Laurencia sp. as a refuge, and higher growth rates that can be achieved by foraging outside Laurencia sp. (Dahlgren \& Eggleston 2000). This ontogenetic habitat shift has a strong influence on the distribution of fish and their survivorship (Dahlgren 1998). The size range of the observed ontogenetic microhabitat shift, 4.0 to $5.0 \mathrm{~cm} \mathrm{TL}$, is within the optimal size range for the microhabitat shift in this nursery system (Dahlgren 1998, Dahlgren \& Eggleston 2000).

Although the ontogenetic microhabitat shift out of Laurencia sp. may make early juvenile Nassau grouper less dependent on the refuge provided by
Laurencia sp., other processes are required to decouple fish density from Laurencia sp. percent cover. We observed variability in fish density among sites to be correlated with the size distribution of fish, with sites containing a disproportionate number of large fish also having higher fish densities. This pattern suggests that size-dependent processes such as growth, mortality, or movement influence population distributions at this time (e.g. Sale et al. 1984, Sale \& Ferrell 1988, Connell \& Jones 1991, Levin 1991, Booth 1992, Wellington 1992, Tupper \& Boutilier 1995). Our study was not designed to determine which size-dependent processes structure the population at this time, but experimental work in this nursery system suggests that several processes may be responsible. Because Nassau grouper growth rates can vary among study sites in this system, and mortality rates are size-dependent, a combination of variable growth and mortality may produce the observed patterns (Dahlgren 1998, Dahlgren \& Eggleston 2000). Moreover, the ontogenetic habitat shift out of the nursery system is expected to be sizedependent and may vary among sites (Eggleston 1995).

The influence of microhabitat characteristics on local distribution and abundance patterns of early postsettlement Nassau grouper and the subsequent influence of size-dependent ecological processes that vary among nursery areas may have important implications for the distribution and abundance of late juvenile and adult Nassau grouper on local and regional scales. Macroalgal nursery habitats are relatively rare around Exuma Sound, Bahamas (Lipcius et al. 1997); therefore, abundance patterns of later juveniles and adults on reefs may reflect the spatial distribution of nursery habitats and variable characteristics of those nursery habitats. The population of Caribbean spiny lobster Panulirus argus, another species that uses macroalgal beds as primary settlement and nursery habitats, shows source/sink metapopulation dynamics, whereby local adult abundance is decoupled from postlarval supply in areas lacking macroalgal beds (sinks), and coupled in sites with abundant nursery habitats (sources) (Lipcius et al. 1997). Similar dynamics may affect the Nassau grouper population. Our finding of a coupling between spatial variability in early juvenile density and size-structure among macroalgal nurseries suggests that different nursery areas may vary in their contribution to the later juvenile and adult populations on nearby reefs. Our study emphasizes the need for a better understanding of the functional role of off-reef nursery systems to reef-associated species, and how nursery areas may vary with respect to microhabitat characteristics, potential growth rates and sizedependent processes (e.g. ontogenetic habitat shifts and predation). This information can then be used to 
examine linkages between critical nursery areas, patch reefs, and offshore reef systems within a source-sink framework in the development of conservation and management strategies for commercially and ecologically important and threatened species such as the Nassau grouper.

Acknowledgements. We thank D. Nadeau for coordinating and conducting band transect censuses, and initial processing of census data. We also thank J. Cordes, W. Elis, L. Etherington, K. Metcalf, M. Montane and N. Seymour for data collection, and the staff of the Caribbean Marine Research Center for logistical support, particularly G. Dennis, T. Bailey and T. Wolcott. The manuscript was improved by comments from J. Gilliam, M. Posey, J. Rice, and 2 anonymous reviewers. Work was funded by the NOAA's National Undersea Research Program, the Perry Institute for Marine Science's Caribbean Marine Research Center, North Carolina State University, The University of North Carolina at Wilmington, and the College of William and Mary.

\section{LITERATURE CITED}

Beets J, Hixon MA (1994) Distribution, persistence, and growth of groupers (Pisces:Serranidae) on artificial and natural patch reefs in the Virgin Islands. Bull Mar Sci 55: 470-483

Bohnsack JA, Bannerot SP (1986) A stationary visual census technique for qualitatively assessing community structure of coral reef fishes. NOAA Tech Rep NMFS 41:1-15

Booth DJ (1992) Larval settlement patterns and preferences by domino damselfish Dascyllus albisella Gill. J Exp Mar Biol Ecol 155:85-104

Carr MH (1994) Effects of macroalgal dynamics on recruitment of a temperate reef fish. Ecology 75:1320-1333

Colin PL, Laroche WA, Brothers EB (1997) Ingress and settlement in the Nassau grouper Epinephelus striatus (Pisces: Serranidae), with relationship to spawning occurrence. Bull Mar Sci 60:656-667

Connell SD, Jones GP (1991) The influence of habitat complexity on postrecruitment processes in a temperate reef fish population. J Exp Mar Biol Ecol 151:271-294

Dahlgren CP (1998) Population dynamics of early juvenile Nassau grouper: an integrated modeling and field study. $\mathrm{PhD}$ dissertation, North Carolina State University, Raleigh

Dahlgren CP, Eggleston DB (2000) Ecological processes underlying ontogenetic habitat shifts in a coral reef fish. Ecology 81:2227-2240

Day RW, Quinn GP (1989) Comparisons of treatments after an analysis of variance in ecology. Ecol Monogr 59:433-463

Doherty PJ (1991) Spatial and temporal patterns in recruitment. In: Sale PF (ed) The ecology of fishes on coral reefs. Academic Press Inc, San Diego, p 261-293

Eggleston DB (1995) Recruitment in Nassau grouper Epinephelus striatus: post-settlement abundance, microhabitat features, and ontogenetic habitat shifts. Mar Ecol Prog Ser 124:9-22

Eggleston DB, Lipcius RN, Grover JJ (1997) Predation and shelter size effects on coral reef fish and spiny lobster prey. Mar Ecol Prog Ser 149:43-59

Eggleston DB, Grover JJ, Lipcius RN (1998) Ontogenetic diet shifts in Nassau grouper: trophic linkages and predatory impact. Bull Mar Sci 63:111-126

Friedlander AM, Parrish JD (1998) Habitat characteristics affecting fish assemblages on a Hawaiian coral reef. J Exp Mar Biol Ecol 224:1-30

Heck KL Jr, Weinstein MP (1989) Feeding habits of juvenile reef fishes associated with Panamanian seagrass meadows. Bull Mar Sci 45:429-436

Herrnkind WF, Butler MJ (1986) Factors regulating postlarval settlement and juvenile microhabitat use by spiny lobsters Panulirus argus. Mar Ecol Prog Ser 34:23-30

Hixon MA (1991) Predation as a process structuring coral reef fish communities. In: Sale PF (ed) The ecology of fishes on coral reefs. Academic Press Inc, San Diego, p 475-508

Hixon MA, Beets JP (1989) Shelter characteristics and Caribbean fish assemblages: experiments with artificial reefs. Bull Mar Sci 44:666-680

Hixon MA, Beets JP (1993) Predation, prey refuges, and the structure of coral-reef fish assemblages. Ecol Monogr 63: $77-101$

IUCN (1996) International Union for Conservation of Nature and Natural Resources) 1996 red list of threatened species. IUCN, Gland

Jones GP (1984) The influence of habitat and behavioural interactions on the local distribution of the wrasse, Pseudolabrus celidotus. Environ Biol Fish 10:43-58

Jones GP (1986) Food availability affects growth in a coral reef fish. Oecologia (Berl) 70:136-139

Jones GP (1991) Post recruitment processes in the ecology of coral reef fish populations: a multifactorial perspective. In: Sale PF (ed) The ecology of fishes on coral reefs. Academic Press Inc, San Diego, p 294-328

Koenig CC, Coleman FC (1998) Absolute abundance and survival of juvenile gags in sea grass beds of the northeastern Gulf of Mexico. Trans Am Fish Soc 127:44-55

Levin PS (1991) Effects of microhabitat on recruitment variation in a Gulf of Maine reef fish. Mar Ecol Prog Ser 75: 183-189

Levin PS (1994) Small scale recruitment variation in a temperate fish: the roles of macrophytes and food supply. Environ Biol Fish 40:271-281

Light PR, Jones GP (1997) Habitat preference in newly settled coral trout (Plectropomus leopardus, Serranidae). Coral Reefs 16:117-126

Lipcius RN, Stockhausen WT, Eggleston DB, Marshall LS Jr, Hickey B (1997) Hydrodynamic decoupling of recruitment, habitat quality and adult abundance in the Caribbean spiny lobster: source-sink dynamics? Mar Freshw Res 48:807-815

Marx JM, Herrnkind WF (1985) Macroalgae (Rhodophyta: Laurencia spp.) as habitat for young spiny lobsters, Panulirus argus. Bull Mar Sci 36:423-431

Morton RM (1990) Community structure, density and standing crop of fishes in a subtropical Australian mangrove area. Mar Biol 105:385-394

Ochi H (1986) Growth of the anemonefish Amphiprion clarkii in temperate waters with special reference to the influence of settling time on the growth of 0-year olds. Mar Biol 92:223-229

Öhman MC, Munday PL, Jones GP, Caley JM (1998) Settlement strategies and distribution patterns of coral-reef fishes. J Exp Mar Biol Ecol 225:219-238

Parrish JD (1989) Fish communities of interacting shallowwater habitats in tropical oceanic regions. Mar Ecol Prog Ser 58:143-160

Pielou EC (1969) Introduction to mathematical ecology. Wiley-Interscience, New York

Ross SW, Moser ML (1995) Life history of juvenile gag, Mycteroperca microlepis, in North Carolina estuaries. Bull Mar Sci 56:222-236 
Sadovy Y, Eklund AM (1999) Synopsis of biological data on the Nassau grouper, Epinephelus striatus (Bloch, 1792), and the jewfish, E. itajara (Lichtenstein, 1822). NOAA Tech Rep NMFS 146:65

Sale PF, Ferrell DJ (1988) Early survivorship of juvenile coral reef fishes. Coral Reefs 7:117-124

Sale PF, Douglas WA, Doherty PJ (1984) Choice of microhabitats by coral reef fishes at settlement. Coral Reefs 3:91-99

Shenker JM, Maddox ED, Wishinski E, Pearl A, Thorrold SR, Smith N (1993) Onshore transport of settlement stage Nassau grouper Epinephelus striatus and other fishes in Exuma Sound, Bahamas. Mar Ecol Prog Ser 98:31-43

Shulman MJ (1984) Resource limitation and recruitment patterns in a coral reef fish assemblage. J Exp Mar Biol Ecol 74:85-109

Sogard SM (1997) Size-selective mortality in the juvenile stage of teleost fishes: a review. Bull Mar Sci 60: 1129-1157

Sokal RR, Rohlf FJ (1995) Biometry. The principles and practice of statistics in biological research, 3rd edn. WH Freeman \& Co, New York

Strauss RE (1979) Reliability of estimates for Ivlev's electivity index, the forage ratio, and a proposed linear index of food selection. Trans Am Fish Soc 108:344-352

Sweatman HPA (1983) Influence of conspecifics on choice of settlement sites by larvae of two pomacentrid fishes (Dascyllus aruanus and D. reticulatus) on coral reefs. Mar Biol $75: 225-229$

Sweatman HPA (1988) Field evidence that settling coral reef fish larvae detect resident fishes using dissolved chemical cues. J Exp Mar Biol Ecol 124:163-174

Editorial responsibility: Kenneth Heck (Contributing Editor), Dauphin Island, Alabama, USA
Sweatman HP, St. John J (1990) Effects of selective settlement and of aggression by residents on distribution of young recruits of two tropical damselfishes. Mar Biol 105: $247-252$

Thresher RE (1983) Habitat effects on reproductive success in a coral reef fish, Acanthochronis polyacanthus (Pomacentridae) Ecology 64:1184-1199

Tolmieri N (1998a) Contrasting effects of microhabitat use on large-scale adult abundance in two families of Caribbean reef fishes. Mar Ecol Prog Ser 167:227-239

Tolmieri N (1998b) The relationship among microhabitat characteristics, recruitment and adult abundance in the stoplight parrotfish, Sparisoma viride, at 3 spatial scales. Bull Mar Sci 62:253-268

Tupper M, Boutilier RG (1995) Effects of habitat on settlement, growth, and postsettlement survival of Atlantic cod (Gadus morhua). Can J Fish Aquat Sci 52:1834-1841

Tupper M, Boutilier RG (1997) Effects of habitat on settlement, growth, predation risk and survival of a temperate reef fish. Mar Ecol Prog Ser 151:225-236

Underwood AJ (1997) Experiments in ecology: their logical design and interpretation using analysis of variance. Cambridge University Press, Cambridge

Wellington GM (1992) Habitat selection and juvenile persistence control the distribution of two closely related Caribbean damselfishes. Oecologia (Berl) 90:500-508

Werner EE, Gilliam JF (1984) The ontogenetic niche and species interactions in size- structured populations. Annu Rev Ecol Syst 15:393-425

Zar JH (1984) Biostatistical analysis, 2nd edn. Prentice-Hall, Inc, Englewood Cliffs, NJ

Submitted: December 1, 1999; Accepted: November 20, 2000 Proofs received from author(s): July 16, 2001 